\title{
Unmanned aerial vehicle-based assessment of cover crop biomass and nitrogen uptake variability
}

\author{
M. Yuan, J.C. Burjel, J. Isermann, N.J. Goeser, and C.M. Pittelkow
}

\begin{abstract}
Cover crops have the potential to reduce nitrate $\left(\mathrm{NO}_{3}\right)$ losses while improving soil quality, yet achieving uniform cover crop establishment can be challenging in the US Midwest. Understanding the variability of cover crop biomass and nitrogen $(\mathrm{N})$ uptake at the fieldscale is an important step in determining potential effects on the following cash crop and benefits to water quality, but efficient and nondestructive methods are lacking. The objective of this study was to evaluate a lightweight unmanned aerial vehicle (UAV) mounted with a multispectral sensor in estimating cover crop (grass species) biomass and $\mathrm{N}$ uptake prior to cover crop termination at four commercial fields in Illinois during the 2017 growing season. Two fields had triticale ( $\times$ Triticosecale Wittmack) before corn (Zea mays L.) and two had cereal rye (Secale cereale L.) before soybean (Glycine max [L.] Merr.). Forty ground-truth biomass samples $\left(1 \mathrm{~m}^{2}\right)$ were collected on the day of each UAV flight across each field. Linear relationships were established between cover crop biomass and $\mathrm{N}$ uptake and four vegetation indices (VIs; Normalized Difference Vegetation Index [NDVI], Green Ratio Vegetation Index [GRVI], Green Normalized Difference Vegetation Index [GNDVI], and Triangular Vegetation Index [TVI]). The fourVIs performed similarly in estimating cover crop biomass and $\mathrm{N}$ uptake ( $R^{2}$ range, 0.42 to 0.93 ; RMSE range, $9.4 \%$ to $27.2 \%$ of the range of biomass or $\mathrm{N}$ uptake). A high degree of within-field variability for NDVI was observed at all fields, with biomass and N uptake at soybean fields ranging from 0 to $1,790 \mathrm{~kg} \mathrm{ha}^{-1}$ and 0 to $48.5 \mathrm{~kg} \mathrm{ha}^{-1}$, respectively, and at corn fields 0 to $840 \mathrm{~kg} \mathrm{ha}^{-1}$ and 0 to $31.5 \mathrm{~kg} \mathrm{ha}^{-1}$, respectively. Because cover crop biomass is often estimated based on hand samples, we also simulated the effects of biomass sampling number $(2,5,10$, or 15$)$ on the probability of reaching different accuracy levels for estimating field means for different field sizes. Under the growing conditions of this single study year and relatively modest biomass accumulation $\left(<1,400 \mathrm{~kg} \mathrm{ha}^{-1}\right)$, results from this preliminary study provide evidence that UAVs are a viable technique to obtain relatively rapid, nondestructive estimates of biomass and $\mathrm{N}$ uptake of two grass cover crops at vegetative stage prior to termination at the field-scale in the US Midwest. This approach could help effectively utilize scarce conservation resources, but further work is needed to evaluate other cover crop species under a wider range of growth conditions.
\end{abstract}

Key words: cereal rye-cover crops-Normalized Difference Vegetation Index (NDVI) remote sensing — unmanned aerial vehicle (UAV)—vegetation indices

Cover crops are recognized as an important agricultural conservation practice for reducing nitrate (NO) losses in the Illinois Nutrient Loss Reduction Strategy (Illinois EPA 2015) and other state-level strategies developed in the US Midwest. However, adoption of cover crops by farmers remains low (Dabney et al. 2001; RoeschMcNally et al. 2017). Farmers remain apprehensive about integrating cover crops crop are spatially and temporally variable (Muñoz et al. 2014), making management decisions more complex during planting and early season growth. Despite these challenges, increased cover crop adoption will be necessary to meet nutrient loss reduction goals in this region.

Cover crop performance is typically assessed in small plot studies following conventional field experiment design (Crandall et al. 2005; Jahanzad et al. 2017; Pantoja et al. 2015, 2016; Restovich et al. 2012). Previous work has found that the total amount of cover crop growth (i.e., biomass accumulation at cover crop termination) can have important and variable impacts on crop yield and water quality outcomes at the small plotscale (Kaspar and Bakker 2015; Finney et al. 2016; Martinez-Feria et al. 2016). Hence, being able to track cover crop growth and estimate biomass at key points may represent an opportunity for improved management. However, achieving uniform cover crop establishment can be challenging in the US Midwest, even in small plot studies, not only leading to spatial variability in growth and $\mathrm{N}$ uptake but also making it more challenging to effectively estimate biomass. Previous work highlights that while spatial variability in cover crop establishment and growth can be large (Muñoz et al. 2014), there have been few attempts to quantify this variability at the field-scale, possibly due to the limitation of traditional measurement techniques. Muñoz et al. (2010) concluded from several studies that assessment of cover crop biomass can be time- and labor-consuming, and measurement accuracy can be heavily influenced by the sampling technique used, cover crop species, and stage of development.

Recent advances in remote sensing technologies and spectral reflectance analysis using various platforms (i.e., satellite and manned aircraft) could enable rapid estimation of cover crop growth and nutrient uptake at larger scales. Vegetation indices (VIs) derived from spectral data have been

into their production systems due to timing and economic issues related to cover crop establishment and termination, required changes in other management factors such as tillage or nitrogen $(\mathrm{N})$ management, or concerns about potential negative impacts on corn (Zea mays L.) or soybean (Glycine $\max$ [L.] Merr.) yields (Roesch-McNally et al. 2017). Cover crop establishment, growth, and subsequent nutrient supply to a cash
Mingwei Yuan is a postdoctoral scholar, Juan C. Burjel is a research assistant, and Cameron M. Pittelkow is an assistant professor in the Department of Crop Sciences, University of Illinois in Urbana, Illinois. Jim Isermann is a field manager with the Soil Health Partnership in Chesterfield, Missouri. Nicholas J. Goeser is vice president of production and sustainability at the National Corn Growers Association in Chesterfield, Missouri. 
widely used to estimate plant biomass and nutrient uptake in various species, including wheat (Triticum aestivum L.), corn, barley (Hordeum vulgare L.), and rice (Oryza sativa L.) (Jensen et al. 2007; Li et al. 2014; Liebisch et al. 2015; Nguyen et al. 2006; Tilly et al. 2015; Yu et al.2013). However, comparatively fewer studies have assessed the performance of different VIs in estimating biochemical and biophysical characteristics in cover crops, especially with unmanned aerial vehicles (UAVs) (Hively et al. 2009; Muñoz et al. 2010). The development of UAVs mounted with multispectral cameras has enabled acquisition of high-resolution images across large areas quickly and repeatedly, at lower cost, and with greater flexibility in terms of flying heights and mission timing compared to satellite and manned aircraft platforms (Pajares 2015). Recently, UAV-based research has been carried out for a number of agronomic applications, including weed mapping (Gómez-Candón et al. 2014; Pena et al. 2013; Torres-Sánchez et al. 2014), N fertilization management (Maresma et al. 2016), and estimation of crop biophysical parameters (i.e., canopy height and yield) (Li et al. 2016; Yu et al. 2016). However, less effort has been made to investigate the within-field variability of cover crop growth or $\mathrm{N}$ uptake prior to termination with UAVs (Hunt et al. 2011; Roth and Streit 2017; Rydberg et al. 2007).

Two management decisions that could benefit from mapping cover crop biomass at the field-scale are selection of cover crop termination date and $\mathrm{N}$ management. Cover crop termination date has an important influence on potential biomass accumulation (e.g., waiting longer to terminate allows for more spring growth). Yet when selecting a termination date in the US Midwest, there is an inherent conflict in simultaneously addressing water quality and crop production goals. Recent work shows that cover crop biomass needs to be large enough to achieve $\mathrm{NO}_{3}$ loss reductions (Martinez-Feria et al. 2016), but small enough to avoid potential $\mathrm{N}$ immobilization issues and potential negative impacts on yield (Pantoja et al. 2016). Although gaining a rapid understanding of cover crop growth might help navigate this apparent tradeoff, there are inherent challenges in capturing dynamics at the field-scale due to the large variability in physical, environmental, and farm management practices as discussed above. In regards to $\mathrm{N}$ management, one possibility is that maps of cover crop growth could be used to identify potential areas of $\mathrm{N}$ immobilization, which in turn could help inform $\mathrm{N}$ management strategies, for example using variable rate $\mathrm{N}$ application.

Within the context of using recently available high-resolution remote sensing technologies to advance conservation management practices in the US Midwest, this study was conducted to evaluate the performance of UAVs equipped with a multispectral sensor in estimating cover crop biomass and $\mathrm{N}$ uptake across four commercial fields in Illinois. Specific objectives included (1) evaluate appropriate indices for estimating cover crop biomass and $\mathrm{N}$ uptake at termination (Normalized Difference Vegetation Index [NDVI], Green Ratio Vegetation Index [GRVI], Green Normalized Difference Vegetation Index [GNDVI], and Triangular Vegetation Index [TVI]); (2) assess within-field variability of cover crop biomass and $\mathrm{N}$ uptake; and (3) investigate the number of biomass samples necessary to accurately estimate the overall mean for different size field areas.

\section{Materials and Methods}

Study Sites and Experimental Design. The experiments were located in four commercial fields managed by collaborating farmers and the Soil Health Partnership in Illinois, United States, during the 2017 growing season. Two field trials adjacent to each other had triticale $(\times$ Triticosecale Wittmack) as a cover crop before corn (Fields 1 and 2), while Fields 3 and 4 had cereal rye (Secale cereale L.) as a cover crop before soybean. Field information and crop management practices are shown in table 1.The predominant soil series at Field 1 and Field 2 was Streator silty clay loam (fine, smectitic, mesic Vertic Endoaquolls), Field 3 was Ipava silt loam (fine, smectitic, mesic Aquic Argiudolls), and Field 4 was Saybrook silt loam (fine-silty, mixed, superactive, mesic Oxyaquic Argiudolls). One field had vertical tillage (Field 4) while the remaining three fields had no-till. The experimental layout at each field was a randomized complete block design with two treatments (cover crop and non-cover crop) replicated four times. Experimental units were large strips (2.1 to 3.6 ha in size).

Image Data Acquisition and Processing. The remote sensing approach used in this study relied on commercially available hardware and software with the goal of being applicable to farmers, land managers, or other conservation professionals. The UAV platform was a 3DR solo drone (Master Airscrew, California) equipped with Parrot Sequoia multispectral sensor (figure 1). The UAV flights were conducted close to the time of termination at each field (table 1). The multispectral sensor captured four separate bands: green $(550 \mathrm{~nm}$, bandwidth 40 $\mathrm{nm})$, red $(660 \mathrm{~nm}$, bandwidth $40 \mathrm{~nm})$, red edge (735 nm, bandwidth $10 \mathrm{~nm}$ ), and near infrared (790 nm, bandwidth $40 \mathrm{~nm}$ ). The flight height was set at $100 \mathrm{~m}$ with a speed of $6 \mathrm{~m} \mathrm{~s}^{-1}$. The average area surveyed for each flight was 9 ha over approximately 12 minutes, thus two to three flights were conducted to obtain complete imagery at each field. At least eight ground control points (GCPs) were evenly distributed prior to each flight to enable enhanced georeferencing of images during postprocessing. The locations of GCPs were determined using a Trimble Geoexplorer 6000 handheld global positioning system (GPS). The GCPs were made of $43 \times 43 \mathrm{~cm}$ foam with an $8 \mathrm{~cm}$ diameter black dot in the middle of the foam. The sampling method utilized here was similar to that in Maresma et al. (2016).

Around 1,000 images were taken during each flight. Images were acquired with a sidelap of at least $70 \%$ and a frontlap of at least $80 \%$. The images were rectified and mosaicked at a spatial resolution of $15 \mathrm{~cm}$ per pixel using Pix4D Mapper Pro software (Pix4D SA, Lausanne, Switzerland). The images were georeferenced with an accuracy level within $10 \mathrm{~cm}$ using the GCP Manager tool in Pix4D. The VI maps were built using the Index Calculator tool within the software.

Four vegetation indices were computed based on the reflectance values in this study: NDVI (Rouse et al. 1974), GRVI (Sripada et al. 2006), GNDVI (Gitelson et al. 1996), and TVI (Broge and Leblanc 2001), calculated by the following equations, respectively:

$$
\begin{aligned}
& \text { NDVI }=\frac{(\text { NIR-Red })}{(\text { NIR }+ \text { Red })}, \\
& \text { GRVI }=\frac{\text { NIR }}{\text { Green }}, \\
& \text { GNDVI }=\frac{(\text { NIR }- \text { Green })}{(\text { NIR }+ \text { Green })}, \text { and }
\end{aligned}
$$




\section{Figure 1}

Images of (a) unmanned aerial vehicle (UAV) equipped with multispectral sensor, (b) example UAV flight at Field 1, and (c) biomass sampling using a $1 \mathrm{~m}^{2}$ quadrat.

(a)

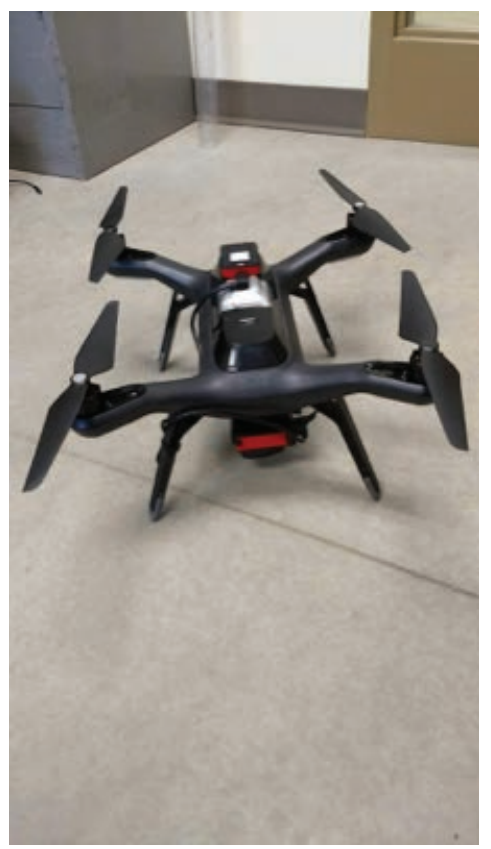

(b)

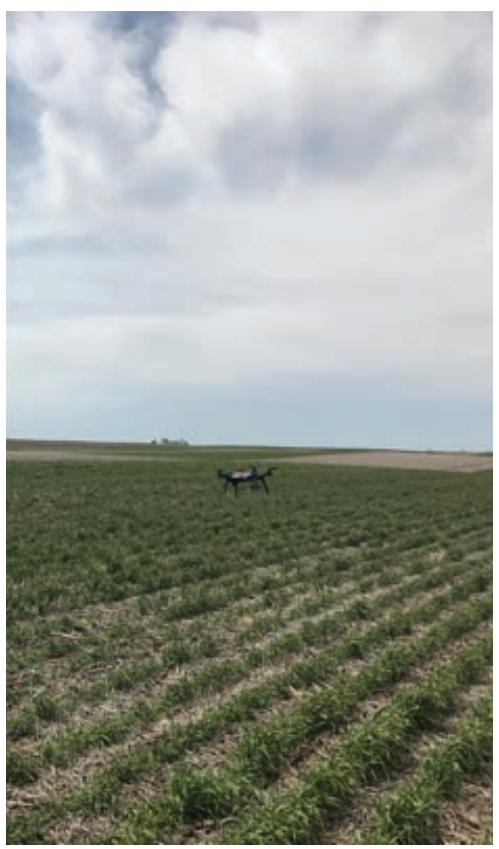

(c)

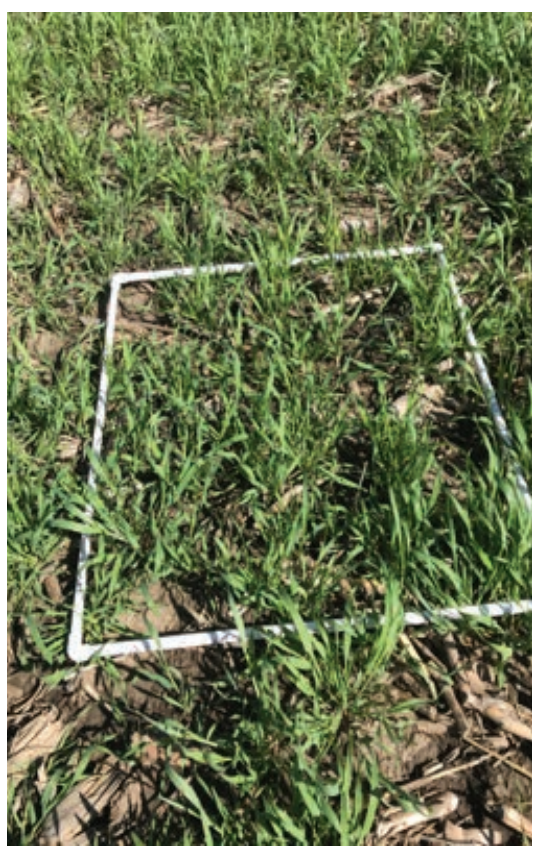

\section{Table 1}

Location and cover crop management information at the four commercial fields used in this study.

\begin{tabular}{|c|c|c|c|c|c|c|c|}
\hline Site & Location & Coordinate & Cash crop & Cover crop & Area (ha) & Sampling date & Termination date \\
\hline Field 1 & Rutland, Illinois & $40^{\circ} 59^{\prime} 45.32^{\prime \prime} \mathrm{N} ; 89^{\circ} 03^{\prime} 42.40^{\prime \prime} \mathrm{W}$ & Corn & Triticale & 19 & April, 21, 2017 & April, 30, 2017 \\
\hline Field 2 & Rutland, Illinois & $40^{\circ} 59^{\prime} 34.59^{\prime \prime} \mathrm{N} ; 89^{\circ} 03^{\prime} 40.81^{\prime \prime} \mathrm{W}$ & Corn & Triticale & 19 & April 26, 2017 & April 30, 2017 \\
\hline Field 4 & Leroy, Illinois & $40^{\circ} 28^{\prime} 25.13^{\prime \prime} \mathrm{N} ; 88^{\circ} 46^{\prime} 12.33^{\prime \prime} \mathrm{W}$ & Soybean & Cereal rye & 29 & April 27, 2017 & April 28, 2017 \\
\hline
\end{tabular}

TVI $=0.5[120($ NIR - Green $)-200($ Red Green)],

where NIR is the reflectance of the near infrared light, Red is the reflectance of the red light, and Green is the reflectance of the green light. The green-based indices like GRVI and GNDVI were selected due to their greater sensitivity to $\mathrm{N}$ deficiency and higher correlation with yield in crops like maize than the red-based indices (Gasparotto et al. 2015). For instance, GRVI is dominant at 1.25 to 2.5 , which reached $98 \%$, and higher GRVI values are usually accompanied with lower NDVI, indicating lower photosynthetic rates (Sivaganesan and Chandrasekaran 2016). In contrast, TVI was reported to be highly robust when crops reach high values of biomass (Prabhakara et al. 2015).
Ground-Truth Sampling. On the same day as UAV flights at each field, biomass samples $\left(1 \mathrm{~m}^{2}\right)$ were collected at 10 locations within each cover crop strip for a total of 40 samples (figure 1c). The sampling locations were evenly distributed across each strip to capture the range of growth conditions being evaluated with each UAV flight. Similarly, in order to develop relationships between cover crop biomass and different VIs, samples were obtained to capture the range of biomass present in each field (i.e., low to high). There was little weed growth in non-cover crop strips, and therefore weed biomass was not sampled. All sampling locations were georeferenced using a Trimble Geoexplorer 6000 handheld GPS. Biomass samples were oven-dried to a constant weight at $70^{\circ} \mathrm{C}$. To determine tissue $\mathrm{N}$ concentration of biomass, 10 of 40 samples covering the full range of observed biomass at each field were analyzed via elemental combustion by Brookside Laboratories, Inc. (New Bremen, Ohio).

Relationships between Vegetation Indices and Cover Crop Biomass and Nitrogen Uptake. Within each field, the values of four VIs at all ground-truth biomass sampling locations were extracted in ArcGIS 10.2 software (ESRI 2013) using "Pixel Inspector" tool from theVI maps. To conduct a two-step approach for model development and evaluation at each field, the 40 biomass samples were randomly divided into a calibration set $(75 \%, n=30)$ and a validation set $(25 \%, n=$ 10). Linear relationships were first developed at each field between each VI and cover crop biomass with the calibration set using $\mathrm{R}$ software version 3.2.1 (R Core Team 2015):

$B=\alpha \times V I+\beta$, 
where $B$ is the cover crop biomass $\left(\mathrm{kg} \mathrm{ha}^{-1}\right)$, $V I$ represents the vegetation index values at the same sampling locations, and $\alpha$ and $\beta$ are regression coefficients.

To estimate $\mathrm{N}$ uptake, the relationship between tissue $\mathrm{N}$ concentration and biomass was first established using linear regression for 10 selected samples at each field covering the range in biomass observations:

$\% \mathrm{~N}=\gamma \times B+\delta$

where $\% \mathrm{~N}$ is the $\mathrm{N}$ concentration (\%) and $\gamma$ and $\delta$ are regression coefficients. Regression coefficients and model fit are reported in figure 2 ( $R^{2}$ range: 0.60 to 0.77 ). Subsequently, $\mathrm{N}$ concentration was estimated using these two developed linear models, with the extracted VI values at all locations:

$\% \mathrm{~N}=\alpha \gamma \times V I+\beta \gamma+\delta$.

Nitrogen uptake was then calculated by multiplying biomass by estimated $\mathrm{N}$ concentration. The fourVIs were also correlated with $\mathrm{N}$ uptake using linear regression models with the calibration set at each field. Coefficients for the fitted models between VIs versus cover crop biomass, $\% \mathrm{~N}$, and $\mathrm{N}$ uptake are reported in table 2. Model validations were performed subsequently using the calibrated models with the validation data sets. The coefficients of determination $\left(R^{2}\right)$ and root mean square error (RMSE) for the calibration and validation data sets were determined to assess the model stability. The RMSE value was provided in the units of measure as well as a percentage of the sample data range (i.e., $\%$ RMSE). All calculations were performed in R (R Development Core Team 2013).

Evaluating the Number of Samples to Accurately Estimate the Field Mean. At present, methods to estimate cover crop biomass for a field typically rely on representative samples being obtained by hand. However, within-field variability may not be captured by this approach. To explore how means based on hand samples compare with means based on field-scale UAV maps, we examined the number of $1 \mathrm{~m}^{2}$ samples that would be necessary to accurately estimate the field mean (i.e., mean based on the biomass maps generated above). The spatial resolution of the NDVI maps was first enlarged from 0.15 $\mathrm{m}$ to $1 \mathrm{~m}$ using the "resample" tool in ArcGIS 10.2 software to align with our $1 \mathrm{~m}^{2}$ biomass quadrats for ground-truth sampling. This

\section{Figure 2}

Relationships between cover crop $\mathrm{N}$ concentration (\%) versus biomass $\left(\mathrm{kg} \mathrm{ha}^{-1}\right)$ close to cover crop termination at four fields $(n=10)$. Regression models indicated in legend correspond to equation 6.

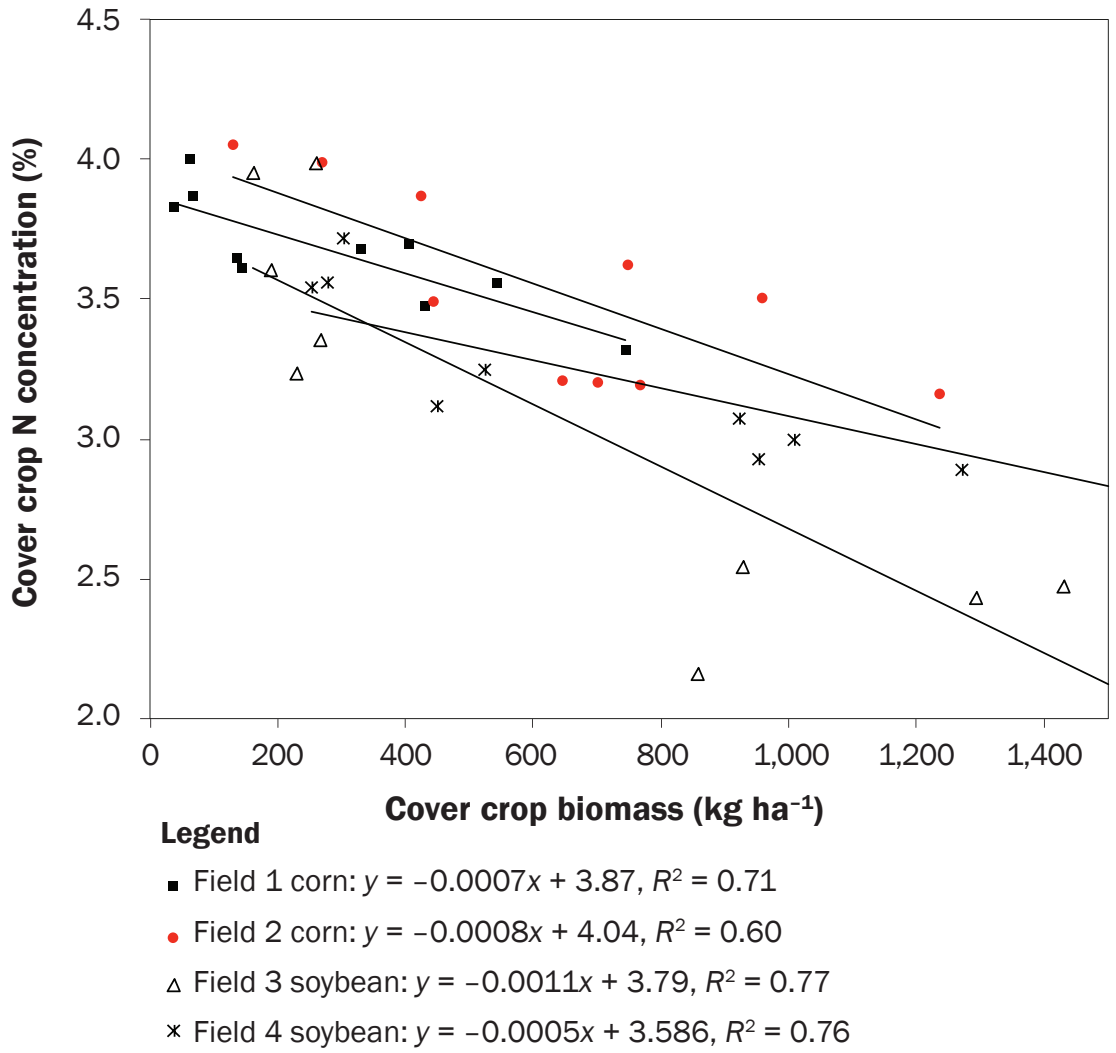

exercise was conducted for a subsection of Field 3 using smaller to larger field areas (0.1, $0.5,1$, and $3 \mathrm{ha}$ ). To assess a realistic range of manual sampling, we simulated 2, 5, 10, and 15 cells (representing $1 \mathrm{~m}^{2}$ biomass samples) being randomly collected 100 different times from NDVI maps using the "datasample" function in Matlab software version R2016a (Mathworks Inc., Sherborn, Massachusetts). The selected NDVI values were converted to cover crop biomass using the linear relationships above. Mean cover crop biomass for each field area was regarded as the "real" cover crop biomass. Normal distributions were fitted to the 100 replications of each sampling strategy using the "Distribution Fitting" App in Matlab. The probability of achieving $60 \%$ and $80 \%$ accuracy levels of the real mean biomass was calculated as the percentage of observations falling within $\pm 20 \%$ or $\pm 40 \%$, respectively, based on fitted probability density functions for each sampling strategy. The accuracy level, i.e., $80 \%$, was defined as the range of $80 \%$ to $120 \%$ of the real mean cover crop biomass.

\section{Results and Discussion}

Vegetation Indices. In general, the range of $R^{2}(0.42$ to 0.93$)$ and RMSE values $(9.4 \%$ to $27.2 \%$ ) of the validation sets suggested that the four VIs could estimate cover crop biomass at time of sampling with satisfactory model performance (table 3). As an example, the fitted linear regression models between NDVI and cover crop biomass (figure 3a) as well as $\mathrm{N}$ uptake (figure $3 \mathrm{~b}$ ) are shown for the two fields with the smallest (Field 1) and largest (Field 4) range of biomass and $\mathrm{N}$ uptake. The fitted models of VIs to estimate cover crop $\mathrm{N}$ uptake were similarly robust among the four indices, except for GNDVI and TVI at Field 2 (table 3). However, no significant difference $(p<0.05)$ was found among the fourVIs in their ability to estimate cover crop biomass and $\mathrm{N}$ uptakes across the four fields with the validation sets. Since NDVI resulted in similar $R^{2}$ but slightly lower RMSE in validation for each field, we used NDVI in the following discussion for simplicity.

Limited studies have been conducted to evaluate the performance of VIs in estimating cover crop biomass and $\mathrm{N}$ uptake 
Table 2

Calibrated model coefficients ( $y=$ Slope $x x+$ Intersect) between vegetation indices (Vls; indicated as $x$ in the equation) versus cover crop biomass, nitrogen concentration $(\% \mathrm{~N})$, and $\mathrm{N}$ uptake (indicated as $y$ ). The "Slope" and "Intersect" values under "Cover crop biomass" and "Cover crop \%N" correspond to those in equations 6 and 7 .

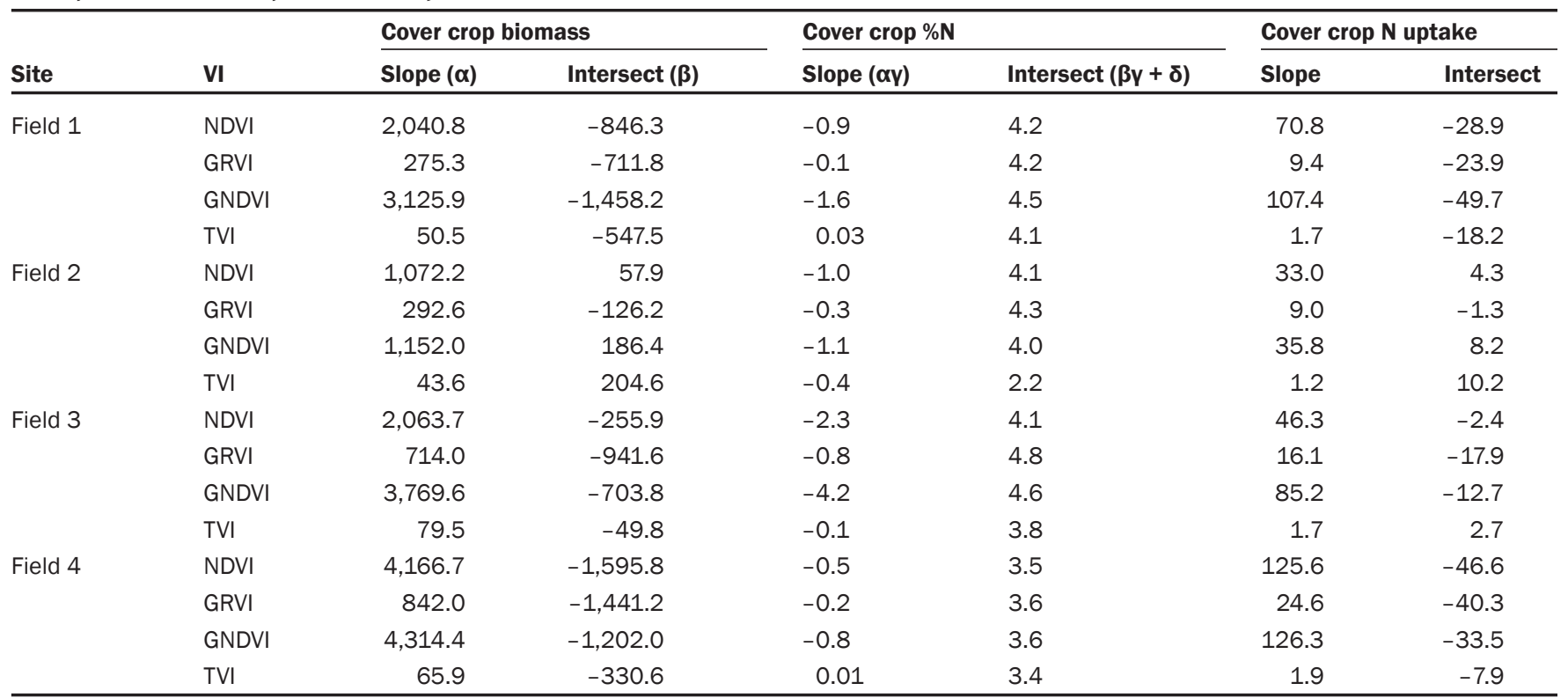

Notes: NDVI = Normalized Difference Vegetation Index. GRVI = Green Ratio Vegetation Index. GNDVI = Green Normalized Difference Vegetation Index. $\mathrm{TVI}=$ Triangular Vegetation Index.

Table 3

Coefficient of determination $\left(R^{2}\right)$ and root mean square error (RMSE, \% of the range of biomass/nitrogen [N] uptake) for model calibrations $(n=30)$ and validations $(\mathrm{n}=10)$ between vegetative indices $(\mathrm{VI})$ versus cover crop biomass and $\mathrm{N}$ uptake.

\begin{tabular}{|c|c|c|c|c|c|c|c|c|c|}
\hline \multirow[b]{2}{*}{ Site } & \multirow[b]{2}{*}{ VI } & \multicolumn{4}{|c|}{ Cover crop biomass } & \multicolumn{4}{|c|}{ Cover crop N uptake } \\
\hline & & $R^{2}$ & RMSE (\%) & $R^{2}$ & RMSE (\%) & $R^{2}$ & RMSE (\%) & $R^{2}$ & RMSE (\%) \\
\hline \multirow[t]{3}{*}{ Field 1} & NDVI & 0.86 & 10.2 & 0.83 & 9.4 & 0.87 & 9.9 & 0.86 & 9.4 \\
\hline & GRVI & 0.92 & 7.6 & 0.85 & 14.2 & 0.93 & 7.5 & 0.90 & 13.8 \\
\hline & GNDVI & 0.88 & 9.3 & 0.83 & 15.1 & 0.89 & 8.9 & 0.89 & 14.6 \\
\hline \multirow{3}{*}{ Field 2} & GRVI & 0.62 & 16.6 & 0.62 & 16.6 & 0.59 & 17.5 & 0.93 & 18.1 \\
\hline & GNDVI & 0.62 & 23.4 & 0.47 & 20.8 & 0.23 & 23.0 & 0.22 & 20.7 \\
\hline & TVI & 0.60 & 28.7 & 0.79 & 21.5 & 0.15 & 27.9 & 0.17 & 23.5 \\
\hline \multirow[t]{2}{*}{ Field 3} & NDVI & 0.74 & 17.9 & 0.80 & 15.8 & 0.80 & 16.9 & 0.86 & 19.3 \\
\hline & GRVI & 0.77 & 16.7 & 0.86 & 13.1 & 0.84 & 15.0 & 0.85 & 22.5 \\
\hline \multirow{3}{*}{ Field 4} & GRVI & 0.63 & 13.4 & 0.54 & 27.2 & 0.63 & 13.5 & 0.83 & 24.8 \\
\hline & GNDVI & 0.65 & 13.0 & 0.63 & 19.0 & 0.65 & 13.0 & 0.63 & 19.0 \\
\hline & TVI & 0.69 & 12.3 & 0.47 & 22.8 & 0.69 & 12.4 & 0.75 & 21.9 \\
\hline
\end{tabular}




\section{Figure 3}

Example relationships between (a) cover crop biomass versus Normalized Difference Vegetation Index (NDVI) and (b) N uptake versus NDVI at cover crop termination. Only fields with the smallest (Field 1) and largest (Field 4) biomass ranges are shown for clarity. At each field 40 biomass samples were collected immediately following the unmanned aerial vehicle (UAV) flight.

(a)

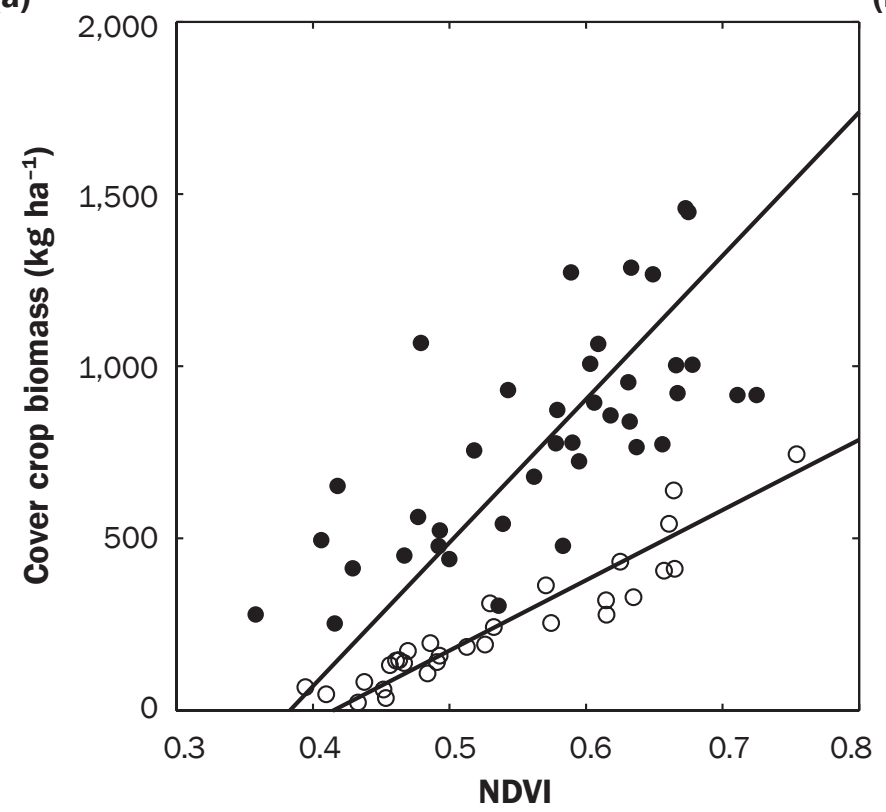

Legend

O Field 1: $y=2,040.8 x-846.3$

- Field 4: $y=4,166.7 x-1,595.8$ (b)

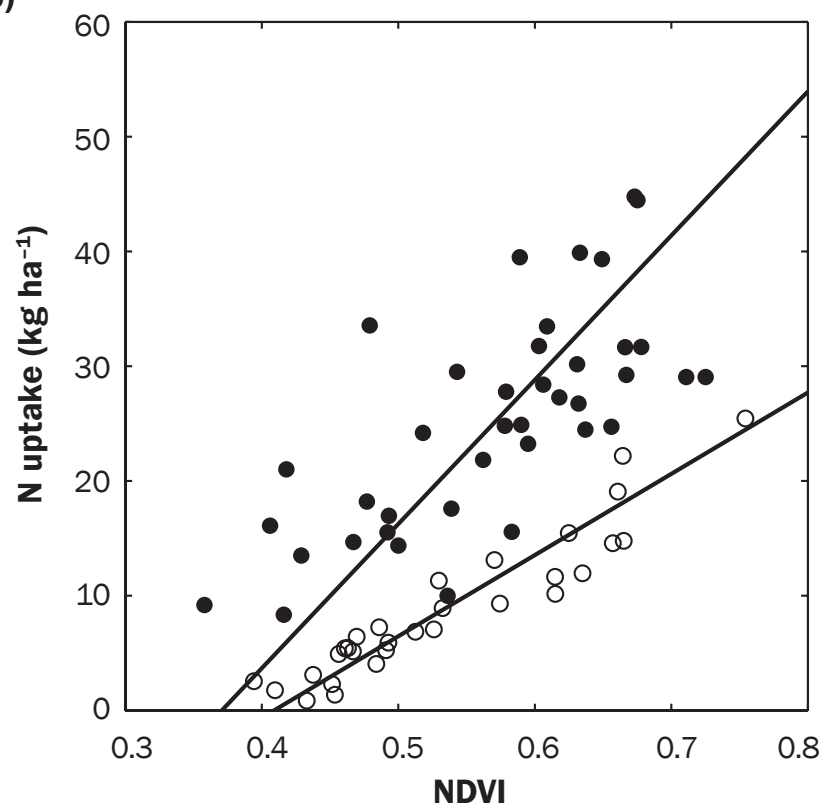

Legend

O Field 1: $y=70.8 x-28.9$

- Field 4: $y=125.6 x-46.6$ using UAVs. Roth and Streit (2017) tested three VIs (NDVI, red edge inflection point, and green red vegetation index) as a nondestructive method to estimate cover crop biomass in nine species (legumes and rarely used dicots) using a UAV-based RGB and NIR photography. They found insignificant correlations between all VIs and biomass in most species, though NDVI slightly outperformed the other two in only one legume species at flowering stage. Using a similar UAV system, Hunt et al. (2011) also detected poor linear correlations between two VIs (NDVI and GNDVI) and biomass in three cover crop species $\left(R^{2}<0.36\right)$, which was mainly caused by the small ranges of biomass and VI determined in the experiment. In contrast, the four VIs tested in this study showed strong linear correlations with both cover crop biomass and $\mathrm{N}$ uptake, and performed similarly between the two cover crop varieties. This difference in results may be explained by previous studies showing VIs often suffer from a lack of consistency and stability across growth stages and have low sensitivity when biochemical and biophysi- cal variables reach high values (Cheng et al. 2014; Li et al. 2014; Naveed and Et 2013; Xu et al. 2014; Yu et al. 2013). Therefore, the relatively strong accuracy among the four VIs in this study might be attributed to the fact that cover crops were still small living green vegetation at termination in this study, thus saturation problems associated with VIs were avoided. Given that cover crops are generally terminated early to minimize yield impacts in the Midwest, these results suggest the use of UAVs combined with a multispectral camera can provide a feasible approach for rapid, nondestructive biomass and nutrient uptake determination for grass cover crops in early vegetative growth stages with modest biomass accumulation.

Variability of Normalized Difference Vegetation Index, Cover Crop Biomass, and Nitrogen Uptake. The NDVI maps at cover crop termination at the four fields are shown in figure 4 . Visually, distinct differences can be detected between the cover crop and non-cover crop strips. At the pixel level, uniformly low NDVI values occurred in the non-cover crop strips, suggesting that there was little background noise from the soil surface or residue remaining from the previous crop. In contrast, a large range of NDVI values occurred in the cover crop strips, representing a mixture of soil surface and living cover crop biomass with various levels of greenness (figure 4).

Large spatial variability was observed for NDVI, cover crop biomass, and $\mathrm{N}$ uptake at the four fields based on density distributions fit to the raw data of all three parameters (figure 5). The mean NDVI at the four fields ranged from 0.34 to 0.61 , while skewness and levels of variation were different among fields (figure 5a). Triticale biomass at the two corn fields was relatively low (Field 1, mean: $190 \mathrm{~kg} \mathrm{ha}^{-1}$, range: 0 to $790 \mathrm{~kg} \mathrm{ha}^{-1}$; Field 2, mean: $530 \mathrm{~kg} \mathrm{ha}^{-1}$, range: 190 to $840 \mathrm{~kg} \mathrm{ha}^{-1}$; figure $5 b$ ). Slightly higher biomass of cereal rye was observed at the soybean fields, with higher levels of variation (Field 3, mean: 620 $\mathrm{kg} \mathrm{ha} \mathrm{h}^{-1}$, range: 310 to $1,790 \mathrm{~kg} \mathrm{ha}^{-1}$; Field 4, mean: $990 \mathrm{~kg} \mathrm{ha}^{-1}$, range: 0 to $1,640 \mathrm{~kg}$ $\mathrm{ha}^{-1}$; figure $5 \mathrm{~b}$ ). Similar trends were found for cover crop $\mathrm{N}$ uptake among the four fields, with the mean values ranging from 4.5 to 


\section{Figure 4}

The Normalized Difference Vegetation Index (NDVI) maps at the four fields at termination. The cover crop (CC) strips were indicated by blue boxes (CC-1 to CC-4), and the conventional strips without cover crop (CONV) were shown with black boxes (CONV-1 to CONV-4).

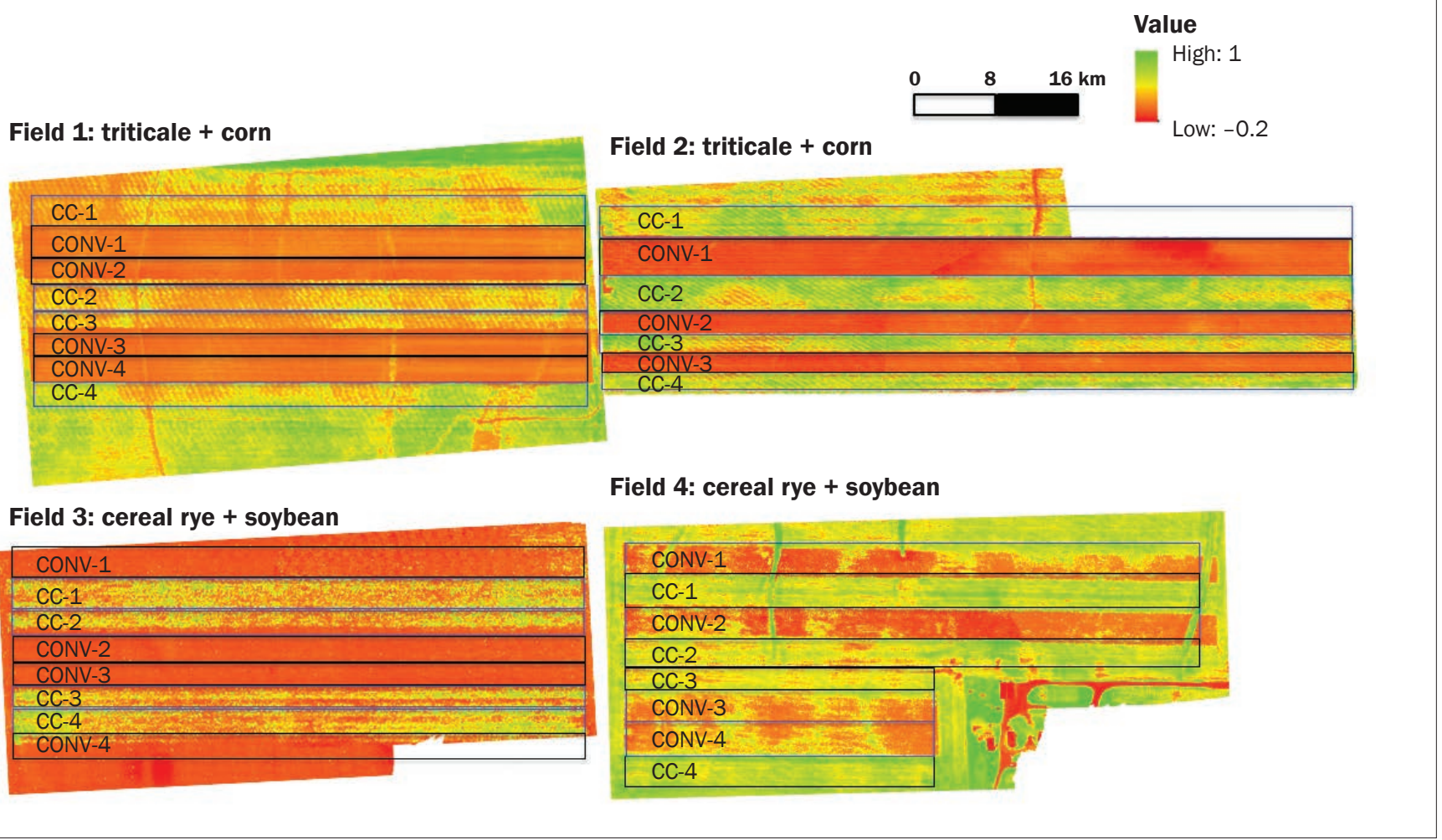

$21.5 \mathrm{~kg} \mathrm{ha}^{-1}$ for triticale and from 19.6 to $33.4 \mathrm{~kg} \mathrm{ha}^{-1}$ for cereal rye (figure $5 \mathrm{c}$ ).

It is well-known that cover crop biomass production and $\mathrm{N}$ accumulation can differ substantially between species, years, and locations. In a six-year experiment in Iowa, Martinez-Feria et al. (2016) reported that rye shoot biomass at termination varied from 120 to $2,499 \mathrm{~kg} \mathrm{ha}^{-1}$ (mean: $1,032 \mathrm{~kg} \mathrm{ha}^{-1}$ ), with rye $\mathrm{N}$ uptake varying from 12.5 to 44.6 $\mathrm{kg} \mathrm{ha}^{-1}$ (mean: $20.4 \mathrm{~kg} \mathrm{ha}^{-1}$ ), mainly depending on winter and early spring weather conditions. Miguez and Bollero (2006) and Crandall et al. (2005) also found large variations in rye biomass (range: 610 to 2,660 $\mathrm{kg} \mathrm{ha} \mathrm{h}^{-1}$ ) and $\mathrm{N}$ uptake (range: 26.1 to 80.5 $\mathrm{kg} \mathrm{ha}^{-1}$ ) under different experimental treatments from 2001 to 2003 at Urbana, Illinois. For triticale, Kaspar and Bakker (2015) summarized a four-year experiment and reported biomass production ranging from 300 to $1,990 \mathrm{~kg} \mathrm{ha}^{-1}$ (mean: $1,045 \mathrm{~kg} \mathrm{ha}^{-1}$ ). Compared with the previous studies, the cover crop biomass and $\mathrm{N}$ uptake values in this study generally fell into the reported ranges, but with slightly lower means for both cereal rye and triticale. Moreover, the species difference was found significant in this study $(p<0.05)$, with lower mean bio- mass and $\mathrm{N}$ uptake in triticale than cereal rye (76\% and 34\% lower in mean biomass and $\mathrm{N}$ uptake, respectively). This was mainly due to the earlier termination of cover crops by the farmers (e.g., the triticale was only around $15 \mathrm{~cm}$ in height at the corn fields). While the majority of previous work has focused on interpreting means, our study provides important insights into the potential benefits of being able to quantify within-field variability of cover crop $\mathrm{N}$ uptake at termination.

Cover crop $\mathrm{N}$ uptake is an important factor determining decomposition rates and $\mathrm{N}$ release following termination, which can influence early season $\mathrm{N}$ availability, particularly if immobilization occurs (Martinez-Feria et al. 2016). However, cover crop $\mathrm{N}$ uptake can vary widely at the field-scale due to heterogeneous landscapes, where multiple variables, including terrain, local water content, soil type, temperature, and microbial activity, interact (Magney et al. 2016). Currently, there are limited options for exploring within-field variability in relation to field means to inform management decisions. Our results provide one example of how two field means may be similar, but variability is different. For example, the mean $\mathrm{N}$ uptake was comparable between
Fields 2 and 3, but the variability was much greater for Field 3. When upper and lower quantiles of the two fields were compared, more extreme high values occurred at Field 3, while lower extremes were found at Field 2, e.g., $25 \%$ of $\mathrm{N}$ uptake values were below $18.8 \mathrm{~kg} \mathrm{ha}^{-1}$ and $25 \%$ were above $24.8 \mathrm{~kg}$ $\mathrm{ha}^{-1}$ for Field 3, whereas lower and upper quantiles were 17.0 and $21.4 \mathrm{~kg} \mathrm{ha}^{-1}$ for Field 2. Quantifying this variability is an important step in understanding potential water quality impacts (where increased cover crop $\mathrm{N}$ uptake is important), as well as yield impacts (where lower cover crop $\mathrm{N}$ uptake may be important). Recently a threshold for maintaining a carbon $(\mathrm{C}): \mathrm{N}$ ratio of 25 has been proposed for cereal rye before corn, corresponding to $1,570 \mathrm{~kg} \mathrm{ha}$ of cereal rye biomass, for limiting the chances of immobilization (Martinez-Feria et al. 2016). Although biomass did not reach this level in our study fields, the approach outlined here could be applied in the future to map cover crop $\mathrm{N}$ uptake to identify areas that might be approaching or exceeding this threshold. Spatial N uptake variability is one example of how UAV platforms might provide new information, which in theory could be used to improve cover crop and $\mathrm{N}$ management 


\section{Figure 5}

Histograms of raw data and fitted density curves of (a) Normalized Difference Vegetation Index (NDVI), (b) cover crop biomass, and (c) nitrogen (N) uptake at the four fields.

(a)

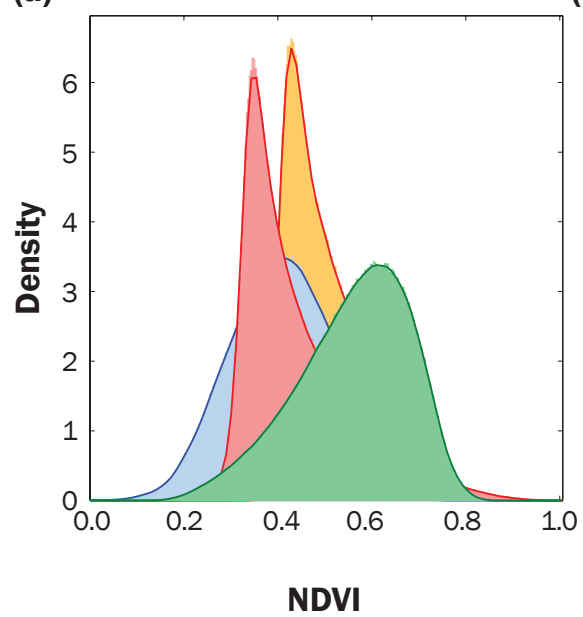

(b)

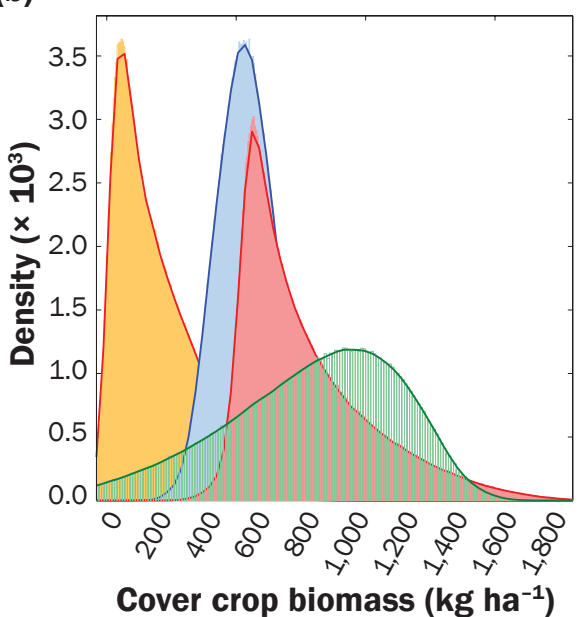

(c)

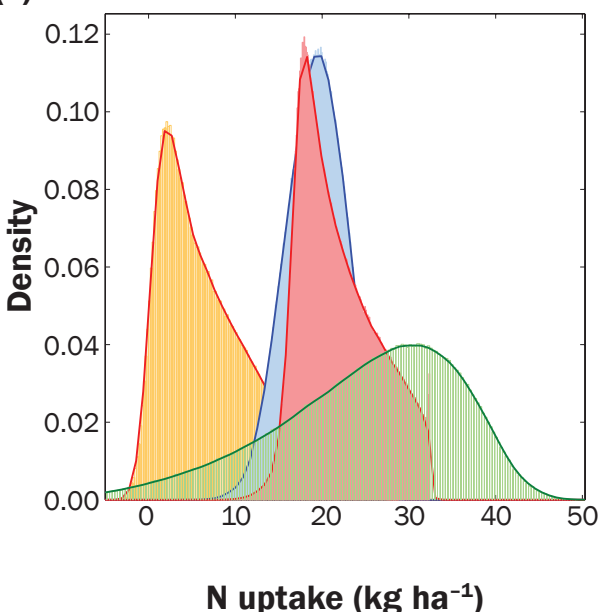

Legend

Field 1 raw data

Field 1 fitted curve

Field 2 raw data

Field 2 fitted curve

decisions. However, quantifying variability is only the first step. To better balance water quality and crop yield goals in the future, further work would be needed to turn this spatial data into actionable management strategies related to cover crop termination or variable rate $\mathrm{N}$ fertilizer management strategies, as discussed above.

Biomass Sampling Strategies for Different Size Field Areas. Our results demonstrate that UAV platforms could be a viable and effective approach for estimating the mean of cover crop biomass while also capturing the variability at field-scale within the particular context of our experimental conditions (grass cover crop species at early vegetative growth stages and modest biomass accumulation). However, a more practical approach employed by farmers and conservation professionals is to estimate cover crop biomass by manual hand sampling. Given the results presented above regarding within-field variability and the fact that farmers are not likely to use UAVs for this purpose in the short-term, from a practical standpoint we explored the number of hand samples necessary to achieve an acceptable level of accuracy in estimating the field mean for different size field areas. Using the 0.1 ha plot area at Field 3 as an example (figure 6), we found that the means of the sampled biomass (indicated by " $\mathrm{m}$ " in the legend) for 100 replications were close to the "real" biomass values with less than $7.6 \%$ of difference, regardless of the sampling numbers. This trend was observed for all sizes of field areas (data not shown). However, these means are based on assuming a population of sampling events (100), but typically each sampling strategy would only be carried out once in a field near the time of cover crop termination. Thus, it is important that increasing the sampling number from 2 to 15 led to decreased variances (indicated by "v" in the legend) (figure 6). Another way of describing this effect is that at the 0.1 ha field area, in order to achieve $80 \%$ accuracy level in estimating mean cover crop biomass, the probability increased from $26 \%$ to $64 \%$ when increasing the sampling times from 2 to 15 (table 4). Similarly, if only $60 \%$ accuracy level was targeted, an increase from $48 \%$ to $92 \%$ was observed when 15 times instead of 2 times of samplings were performed. In contrast, when increasing sampling numbers from 10 to 15 , the probabilities were only enhanced by $2.2 \%$ and $6.7 \%$ for $60 \%$ and $80 \%$ accuracy levels, respectively, which was almost negligible (table 4).

When enlarging the field area, the changes in probability at a certain accuracy level varied depending on the number of samples (table 4). Taking 2, 10, or 15 samples, the probabilities slightly increased or remained unchanged from small ranging to larger field areas at $60 \%$ or $80 \%$ accuracy level, while an opposite trend was found if only 5 samples were obtained. In general, when increasing the sampling area from 0.1 to 3 ha, the probabilities were comparable with less than 15\% of difference at the targeted accuracy level for estimating cover crop biomass.

Based on these results, we found that increasing the number of samples could increase the probability at the targeted accuracy level for estimating cover crop biomass, but the increase was not substantial when the sampling number exceeded 10. Meanwhile, increasing the sampling area did not largely affect the probability at certain accuracy level and sampling numbers. For on-farm applications, this evaluation provides information that can be factored into determining an acceptable number of samples for estimating cover crop biomass at different field areas. For instance, if $80 \%$ accuracy level for biomass estimates is desired, and more than $50 \%$ probability within this level is considered acceptable at 3 ha of sampling area, then 10 times of sampling should be sufficient for estimating cover crop biomass (table 4). The acceptable number of samples will therefore depend on the targeted accuracy level and acceptable probability within this level, which can be arbitrarily determined by farmers or conservation professionals aiming to estimate cover crop biomass at the field-scale.

\section{Summary and Conclusions}

Cover crops play a central role in efforts to reduce $\mathrm{N}$ losses and simultaneously improve 


\section{Figure 6}

Fitted normal distributions of cover crop biomass from 0.1 ha sampling area at Field 3 with different numbers of samples repeated for 100 times. Vertical solid line indicated the mean of the cover crop biomass from 0.1 ha sampling area, and black and red dashed lines indicated the $80 \%$ and $60 \%$ of accuracy levels of estimates, respectively. The letter " $m$ " indicated the mean of the fitted normal distribution for different sampling times, and " $v$ " represented the variance of the distribution.

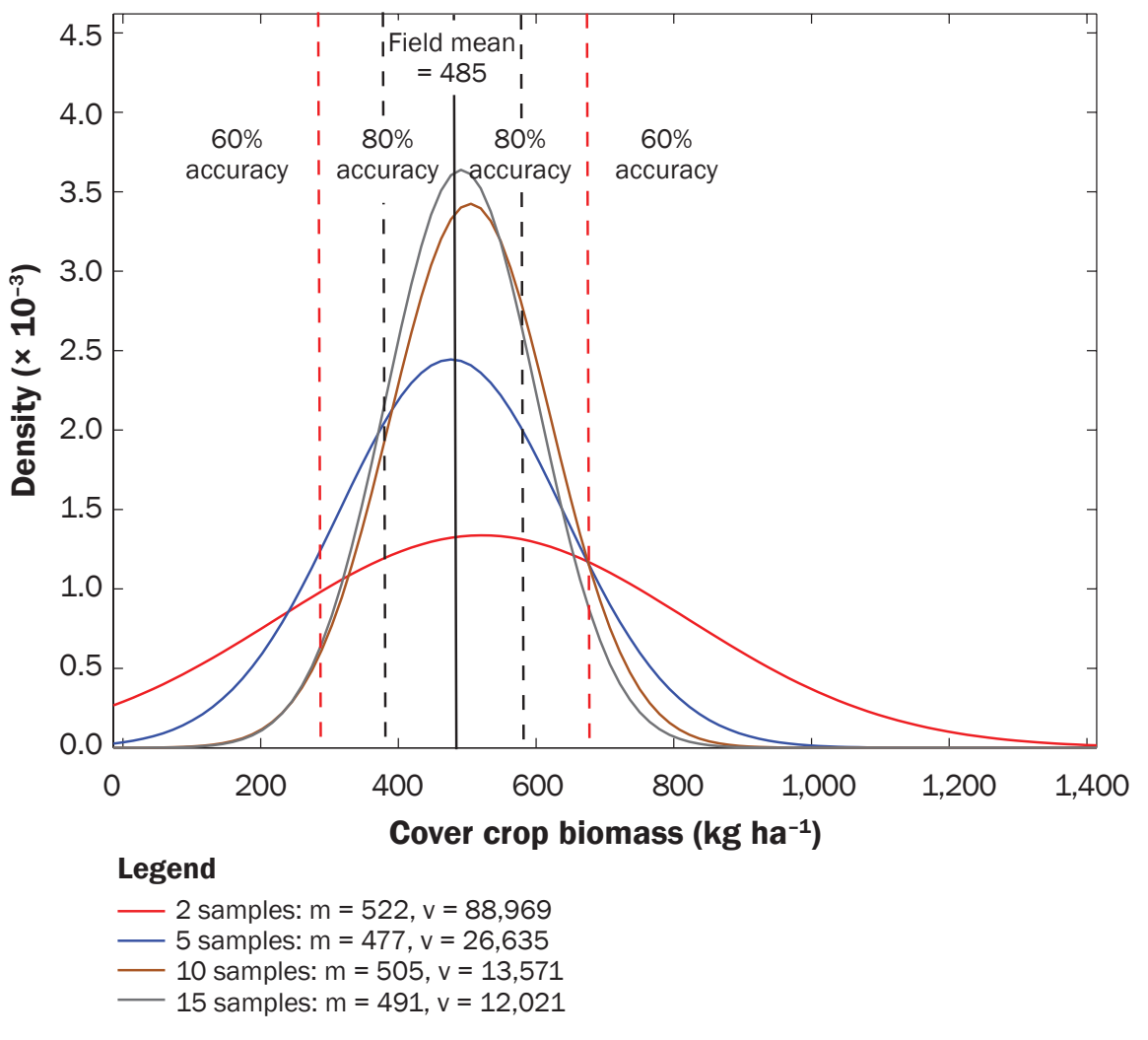

soil quality. Methods to quantify the spatial variability of cover crop biomass and $\mathrm{N}$ uptake at the field-scale could help improve cover crop management practices by identifying potential tradeoffs between crop production and environmental quality goals. The combination of a UAV and multispectral sensor employed in this study proved to be a successful tool for nondestructive estimation of cover crop biomass and $\mathrm{N}$ uptake in two grass cover crops in vegetative growth stages with modest biomass accumulation prior to cover crop termination. Strong linear relationships were found between four VIs (NDVI, GNDVI, RVI, and TVI) and cover crop biomass/N uptake ( $R^{2}$ range, 0.42 to 0.93 ; RMSE range, $9.4 \%$ to $27.2 \%$ of the range of biomass $/ \mathrm{N}$ uptake; $p<0.01)$. No significant difference was detected for the estimative ability of the fourVIs when averaged across the fields. Large spatial variability was reported for NDVI, cover crop biomass, and $\mathrm{N}$ uptake at termination at each field, highlighting the potential benefits of utilizing UAVs to develop spatially explicit estimates of cover crop performance and two fields of data for each species, thus future research is needed to further evaluate the robustness and stability of this method under various weather, soil, and cover crop management conditions. This study also provided a quantitative example for conservation professionals to determine the optimum biomass sampling number based on their targeted accuracy level using the spatial maps of cover crop biomass generated by the UAV system. It is anticipated that continued efforts to combine UAV tools with other spatially explicit farm management and crop performance data will provide important information to agricultural and environmental scientists working to improve conservation programs.

\section{References}

Broge, N.H., and E. Leblanc. 2001. Comparing prediction power and stability of broadband and hyperspectral vegetation indices for estimation of green leaf area index and canopy chlorophyll density. Remote Sensing of Environment 76(2):156-172.

Cheng, T., B. Rivard, A.G. Sánchez-Azofeifa, J.-B. Féret, S. Jacquemoud, and S.L. Ustin. 2014. Deriving leaf mass per area (LMA) from foliar reflectance across a variety of plant species using continuous wavelet analysis. ISPRS Journal of Photogrammetry and Remote Sensing 87(2014):28-38.

Crandall, S.M., M.L. Ruffo, and G.A. Bollero. 2005. Cropping system and nitrogen dynamics under a cereal winter cover crop preceding corn. Plant and Soil 268(1):209-219.

Dabney, S.M., J.A. Delgado, and D.W. Reeves. 2001. Using winter cover crops to improve soil and water quality. Communications in Soil Science and Plant Analysis 32(7-8):1221-1250.

ESRI (Environmental Systems Research Institute). 2013. ArcGIS Desktop: Release 10.2. Redlands, CA: Environmental Systems Research Institute.

\section{Table 4}

Probability of reaching different accuracy levels of mean cover crop biomass based on different number of samples and small to large field areas.

\begin{tabular}{|c|c|c|c|c|c|c|c|c|}
\hline \multirow[b]{5}{*}{ Sample number } & \multicolumn{8}{|c|}{ Probability } \\
\hline & \multicolumn{8}{|c|}{$\underline{\text { Field area (ha) }}$} \\
\hline & \multicolumn{2}{|l|}{0.1} & \multicolumn{2}{|c|}{0.5} & \multicolumn{2}{|l|}{1} & \multicolumn{2}{|l|}{3} \\
\hline & \multicolumn{8}{|c|}{ Accuracy level (\%) } \\
\hline & 60 & 80 & 60 & 80 & 60 & 80 & 60 & 80 \\
\hline 2 & 48 & 26 & 58 & 31 & 54 & 29 & 52 & 28 \\
\hline 5 & 77 & 46 & 72 & 41 & 73 & 42 & 69 & 39 \\
\hline 10 & 90 & 60 & 92 & 62 & 90 & 59 & 90 & 59 \\
\hline 15 & 92 & 64 & 97 & 71 & 96 & 70 & 98 & 74 \\
\hline
\end{tabular}


Finney, D.M., C.M. White, and J.P. Kaye. 2016. Biomass production and carbon/nitrogen ratio influence ecosystem services from cover crop mixtures. Agronomy Journal 108(1):39-52.

Gasparotto, A. de C., M.R. Nanni, C.A. da Silva Junior, E. Cesar, F. Romagnoli, A.A. da Silva, and G.C. Guirado. 2015. Using GNIR and RNIR extracted by digital images to detect different levels of nitrogen in corn. Journal of Agronomy 14(2):62-71.

Gitelson, A.A., Y.J. Kaufman, and M.N. Merzlyak. 1996. Use of a green channel in remote sensing of global vegetation from EOS-MODIS. Remote Sensing of Environment 58(3):289-298

Gómez-Candón, D., A.I. De Castro, and F. López-Granados. 2014. Assessing the accuracy of mosaics from unmanned aerial vehicle (UAV) imagery for precision agriculture purposes in wheat. Precision Agriculture 15(1):44-56.

Hively, W.D., M. Lang, G.W. McCarty, J. Keppler, A. Sadeghi, and L.L. McConnell. 2009. Using satellite remote sensing to estimate winter cover crop nutrient uptake efficiency. Journal of Soil and Water Conservation 64(5):303-313, doi:10.2489/jswc.64.5.303.

Hunt, E.R., W.D. Hively, G.W. Mccarty, C.S.T. Daughtry, P.J. Forrestal, R.J. Kratochvil, J.L. Carr, N.F. Allen, J.R. Fox-rabinovitz, and C.D. Miller. 2011. NIR-green-blue high-resolution digital images for assessment of winter cover crop biomass. GIScience and Remote Sensing 48(1):86-98.

Illinois EPA (Environmental Protection Agency). 2015. Illinois Nutrient Loss Reduction Strategy (INLRS). Springfield, IL: Illinois Environmental Protection Agency. https://www2.illinois.gov/epa/Documents/ iepa/water-quality/watershed-management/nlrs/nlrsfinal-revised-083115.pdf.

Jahanzad, E., A.V. Barker, M. Hashemi, A. Sadeghpour, and T. Eaton. 2017. Forage radish and winter pea cover crops outperformed rye in a potato cropping system. Agronomy Journal 109(2):646-653.

Jensen, T., A. Apan, F. Young, and L. Zeller. 2007. Detecting the attributes of a wheat crop using digital imagery acquired from a low-altitude platform. Computers and Electronics in Agriculture 59(2007):66-77.

Kaspar, T.C., and M.G. Bakker. 2015. Biomass production of 12 winter cereal cover crop cultivars and their effect on subsequent no-till corn yield. Journal of Soil and Water Conservation 70(6):353-364, doi:10.2489/ jswc.70.6.353.

Li, F., Y. Miao, G. Feng, F.Yuan, S. Yue, X. Gao, Y. Liu, B. Liu, S.L. Ustin, and X. Chen. 2014. Improving estimation of summer maize nitrogen status with red edge-based spectral vegetation indices. Field Crops Research 157(2014):111-123

Li, W., Z. Niu, H. Chen, D. Li, M. Wu, and W. Zhao. 2016. Remote estimation of canopy height and aboveground biomass of maize using high-resolution stereo images from a low-cost unmanned aerial vehicle system. Ecological Indicators 67(2016):637-648.
Liebisch, F., N. Kirchgessner, D. Schneider, A. Walter, and A. Hund. 2015. Remote, aerial phenotyping of maize traits with a mobile multi-sensor approach. Plant Methods 11(9).

Magney, T.S., J.U.H. Eitel, and L.A.Vierling. 2016. Mapping wheat nitrogen uptake from RapidEye vegetation indices. Precision Agriculture (2016):1-23

Maresma, Á., M. Ariza, E. Martínez, J. Lloveras, and J. Martínez-Casasnovas. 2016. Analysis of vegetation indices to determine nitrogen application and yield prediction in maize (Zea mays L.) from a standard UAV service. Remote Sensing 8(12):973.

Martinez-Feria, R.A., R. Dietzel, M. Liebman, M.J. Helmers, and S.V. Archontoulis. 2016. Rye cover crop effects on maize: A system-level analysis. Field Crops Research 196(2016):145-159.

Miguez, F.E., and G.A. Bollero. 2006. Winter cover crops in Illinois: Evaluation of ecophysiological characteristics of corn. Crop Science 46(4):1536-1545.

Muñoz, J.D., A.O. Finley, R. Gehl, and S. Kravchenko Sasha. 2010. Nonlinear hierarchical models for predicting cover crop biomass using Normalized Difference Vegetation Index. Remote Sensing of Environment 114(12):2833-2840

Muñoz, J.D., J.P. Steibel, S. Snapp, and A.N. Kravchenko. 2014. Cover crop effect on corn growth and yield as influenced by topography. Agriculture, Ecosystems and Environment 189(2014):229-239.

Naveed, M., and T. Et. 2013. Hyperspectral estimation model for nitrogen contents of summer corn leaves under rainred conditions. Pakistan Journal of Botany 45(5):1623-1630.

Nguyen, H.T., J.H. Kim, A.T. Nguyen, L.T. Nguyen, J.C. Shin, and B.-W. Lee. 2006. Using canopy reflectance and partial least squares regression to calculate within-field statistical variation in crop growth and nitrogen status of rice. Precision Agriculture 7(4):249-264.

Pajares, G. 2015. Overview and current status of remote sensing applications based on unmanned aerial vehicles (UAVs). Photogrammetric Engineering \& Remote Sensing 81(April):281-330.

Pantoja, J.L., K.P. Woli, J.E. Sawyer, and D.W. Barker. 2015 Corn nitrogen fertilization requirement and cornsoybean productivity with a rye cover crop. Soil Science Society of America Journal 79(5):1482-1495.

Pantoja, J.L., K.P. Woli, J.E. Sawyer, and D.W. Barker. 2016. Winter rye cover crop biomass production, degradation, and nitrogen recycling. Agronomy Journal 108(2):841-853.

Pena, J.M., J. Torres-Sannchez, A.I. de Castro, M. Kelly, and F. Lopez-Granados. 2013. Weed mapping in early-season maize fields using object-based analysis of unmanned aerial vehicle (UAV) images. PLoS ONE 8(10):1-11.

Prabhakara, K., W.D. Hively, and G.W. McCarty. 2015. Evaluating the relationship between biomass, percent groundcover and remote sensing indices across six winter cover crop fields in Maryland, United States.
International Journal of Applied Earth Observation and Geoinformation 39(2015):88-102.

R Core Team. 2015. R: A language and environment for statistical computing. Vienna: R Foundation for Statistical Computing. https://www.R-project.org.

Restovich, S.B., A.E. Andriulo, and S.I. Portela. 2012. Introduction of cover crops in a maize-soybean rotation of the Humid Pampas: Effect on nitrogen and water dynamics. Field Crops Research 128(2012):62-70.

Roesch-McNally, G.E., A.D. Basche, J.G. Arbuckle, J.C. Tyndall, F.E. Miguez, T. Bowman, and R. Clay. 2017. The trouble with cover crops: Farmers' experiences with overcoming barriers to adoption. Renewable Agriculture and Food Systems (2017):1-12.

Roth, L., and B. Streit. 2017. Predicting cover crop biomass by lightweight UAS-based RGB and NIR photography: An applied photogrammetric approach. Precision Agriculture 19(1):1-22.

Rouse,J.W., R.H.Haas, and D.W.Deering. 1974. Monitoring vegetation systems in the Great Plains with ERTS. In ERTS 3rd Symposium, NASA SP-351,Vol. 1, 309-317. Goddard Space Flight Centre, Greenbelt, Maryland.

Rydberg, A., M. Söderström, O. Hagner, and T. Börjesson. 2007. Field specific overview of crops using UAV. 6th European Conference in Precision Agriculture January:357-364.

Sivaganesan, S., and M. Chandrasekaran. 2016. Impact of various compression ratio on the compression ignition engine with diesel and mahua biodiesel. International Journal of ChemTech Research 9(11):63-70.

Sripada, R.P., R.W. Heiniger, J.G. White, and A.D. Meijer. 2006. Aerial color infrared photography for determining early in-season nitrogen requirements in corn. Agronomy Journal 98(4):968-977.

Tilly, N., H. Aasen, and G. Bareth. 2015. Fusion of plant height and vegetation indices for the estimation of barley biomass. Remote Sensing 7(2015):11449-11480.

Torres-Sánchez, J., J.M. Peña, A.I. de Castro, and F. LópezGranados. 2014. Multi-temporal mapping of the vegetation fraction in early-season wheat fields using images from UAV. Computers and Electronics in Agriculture 103(2014):104-113.

Xu, X., C. Zhao, J.Wang, J. Zhang, and X. Song. 2014. Using optimal combination method and in situ hyperspectral measurements to estimate leaf nitrogen concentration in barley. Precision Agriculture 15(2):227-240.

Yu, K., F. Li, M.L. Gnyp, Y. Miao, G. Bareth, and X. Chen. 2013. Remotely detecting canopy nitrogen concentration and uptake of paddy rice in the Northeast China Plain. ISPRS Journal of Photogrammetry and Remote Sensing 78(2013):102-115.

Yu, N., L. Li, N. Schmitz, L.F. Tian, J.A. Greenberg, and B.W. Diers. 2016. Development of methods to improve soybean yield estimation and predict plant maturity with an unmanned aerial vehicle based platform. Remote Sensing of Environment 187(2016):91-101. 